TITLE:

\title{
Disruption of multidrug and toxin extrusion MATE1 potentiates cisplatin-induced nephrotoxicity.
}

\section{$\operatorname{AUTHOR}(\mathrm{S})$ :}

Nakamura, Takanori; Yonezawa, Atsushi;

Hashimoto, Shinya; Katsura, Toshiya; Inui, Ken-Ichi

\section{CITATION:}

Nakamura, Takanori ...[et al]. Disruption of multidrug and toxin extrusion MATE1 potentiates cisplatin-induced nephrotoxicity.. Biochemical pharmacology 2010, 80(11): 1762-1767

ISSUE DATE:

2010-12-01

URL:

http://hdl.handle.net/2433/131801

\section{RIGHT:}

(c) 2010 Elsevier Inc.; この論文は出版社版でありません。引用の際には 出版社版をご確認ご利用ください。; This is not the published version. Please cite only the published version. 
Disruption of multidrug and toxin extrusion MATE1 potentiates cisplatin-induced nephrotoxicity

Takanori Nakamura $^{1}$, Atsushi Yonezawa ${ }^{1}$, Shinya Hashimoto ${ }^{1}$, Toshiya Katsura ${ }^{1}$, Ken-ichi Inui $^{1,2}$

${ }^{1}$ Department of Pharmacy, Kyoto University Hospital, Faculty of Medicine, Sakyo-ku, Kyoto 606-8507, Japan; ${ }^{2}$ Kyoto Pharmaceutical University, Yamashina-ku, Kyoto 607-8414, Japan

Corresponding author: Professor Ken-ichi Inui, Ph.D.

Department of Pharmacy

Kyoto University Hospital

Sakyo-ku, Kyoto 606-8507, Japan

TEL number: +81-75-751-3577

FAX number: +81-75-751-4207

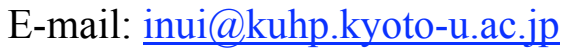

Classification: Toxicology 


\begin{abstract}
Multidrug and toxin extrusion 1 (MATE1/SLC47A1) is expressed in the brush-border membrane of renal proximal tubules and mediates the efflux of cationic drugs. In the present study, the role of MATE1 in the nephrotoxicity of cisplatin was investigated in vivo and in vitro. Cisplatin $(15 \mathrm{mg} / \mathrm{kg})$ was administered intraperitoneally to wild-type (Mate1(+/+)) and Mate1 knockout (Mate1(-/-)) mice. Lifespan was significantly shorter in Mate1(-/-) mice than Mate1(+/+) mice. Three days after the administration of cisplatin, plasma creatinine and blood urea nitrogen $(\mathrm{BUN})$ levels were increased in both Mate1(+/+) and Mate1(-/-) mice compared with vehicle-treated controls, and creatinine clearance was decreased. Moreover, a significant rise in creatinine and BUN levels was observed in cisplatin-treated Mate1(-/-) mice in comparison to Mate1(+/+) mice. A pharmacokinetic analysis revealed the plasma concentration and renal accumulation of cisplatin to be higher in Mate1(-/-) mice than Mate1(+/+) mice $1 \mathrm{~h}$ after a single intravenous administration of cisplatin $(0.5 \mathrm{mg} / \mathrm{kg})$. Furthermore, the combination of a selective MATE inhibitor, pyrimethamine, with cisplatin also elevated creatinine and BUN levels compared to cisplatin alone. In experiments in vitro, the cellular uptake of cisplatin was stimulated by the expression of mouse MATE1 as well as organic cation transporters OCT1 and OCT2. In conclusion, MATE1 mediates the efflux of cisplatin and is involved in cisplatin-induced nephrotoxicity.
\end{abstract}

Key words; Platinum agent, Adverse effect, Organic cation transporter, $\mathrm{H}^{+}$/organic cation antiporter, Renal handling, Pharmacokinetics 


\section{Introduction}

The platinum-based anticancer drug cis-diamminedichloroplatinum II (cisplatin) has been used clinically for over 30 years, and continues to play an essential role in chemotherapy against malignant solid tumors of the lung, bladder, colon, testis and brain. However, severe nephrotoxicity limits its application. An increase in the serum creatinine concentration has been reported in $41 \%$ of patients treated with a high dose of cisplatin [1]. Experiments with rats revealed that renal damage from cisplatin occurred primarily in proximal tubules [2]. In addition, a pharmacokinetic study showed that concentration of cisplatin was higher in renal tissue than in other tissues or plasma [3]. These reports suggested transporters expressed in renal proximal tubular epithelial cells to be involved in the nephrotoxicity of cisplatin.

Human organic cation transporter 2 (hOCT2/SLC22A2) is expressed in the basolateral membrane of proximal tubules and mediates the accumulation of various cationic drugs in the kidney [4, 5]. Human multidrug and toxin extrusion 1 (hMATE1/SLC47A1) and hMATE2-K (SLC47A2) are expressed in the brush-border membrane of renal proximal tubules [6, 7], and transport organic cations with an oppositely directed $\mathrm{H}^{+}$gradient as a driving force [8]. A species difference in the tissue distribution of OCT and MATE is known. In mice, not only OCT2 but also OCT1 is expressed in the kidney $[9,10]$. Mouse (m) MATE1 is expressed in renal proximal tubules [6]. MATE2-K is not found in mice. Recently, we generated Mate1 knockout (Mate1(-/-)) mice, and showed that MATE1 plays a predominant role in the renal tubular secretion of metformin [11]. OCT2, MATE1 and MATE2-K are involved in the renal handling of cationic drugs.

The mechanism behind the cellular uptake of cisplatin has been investigated in renal epithelial cells. Previous reports showed that the expression of OCT2 enhanced markedly the cellular uptake of cisplatin [12-14]. Recently, it was reported that the cumulative urinary excretion and nephrotoxicity of cisplatin were reduced in Oct1/2 double-knockout mice [15]. 
In addition, the coadministration of OCT substrates, imatinib and cimetidine, suppressed the nephrotoxicity $[16,17]$. Based on these reports, uptake via OCT2 is a determinant of the nephrotoxicity induced by cisplatin. The substrate specificities of OCT2 and MATEs are similar [18-20]. Therefore, MATEs could also transport cisplatin and affect its nephrotoxicity. However, the role of efflux transporters in the nephrotoxicity of cisplatin is still unclear.

In the present study, we investigated the involvement of MATE1 in the renal accumulation and nephrotoxicity of cisplatin by using Mate1(-/-) mice and a specific MATE inhibitor, pyrimethamine [21]. In addition, the uptake of cisplatin by mOCT1, mOCT2 and mMATE1 was also examined in an in vitro expression system.

\section{Materials and Methods}

\subsection{Animals}

Mate1(-/-) mice were generated previously [11]. All mice used in the experiments were wild-type (Mate1(+/+)) or Mate1 (-/-) males with the same genetic background (C57BL/6) between 11 and 15 weeks of age. The animals were fed normal pellet food ad libitum, and given water freely. The animal experiments were conducted in accordance with the "Guidelines for Animal Experiments of Kyoto University." All protocols were approved by the Animal Research Committee, Graduate School of Medicine, Kyoto University.

\subsection{Nephrotoxicity and hepatotoxicity of cisplatin}

Mice were administered intraperitoneally cisplatin $(15 \mathrm{mg} / \mathrm{kg})\left(\mathrm{Randa}^{\circledR}\right.$; Nippon Kayaku Co., Ltd., Tokyo, Japan). Pyrimethamine (0.5 mg/kg) (MP Biomedicals, Solon, OH) was also injected intraperitoneally $1 \mathrm{~h}$ before the administration of cisplatin. Control mice were 
administered the equivalent volume of saline. Two days after the administration of cisplatin, mice were maintained in metabolic cages for $24 \mathrm{~h}$ to determine the urinary levels of creatinine. Blood and urine samples were collected at the end of this period. For the measurement of creatinine, blood urea nitrogen (BUN), aspartate aminotransferase (AST) and alanine aminotransferase (ALT) levels, we used commercial kits (Wako Pure Chemical Industries, Osaka, Japan).

\subsection{Renal and hepatic accumulation of cisplatin}

Cisplatin $(0.5 \mathrm{mg} / \mathrm{kg})$ was administered as a bolus via the catheterized right femoral vein under pentobarbital anesthesia. Blood was sampled from the abdominal aorta $1 \mathrm{~h}$ after the administration. The kidney and liver were then immediately collected, gently washed, weighed and homogenized in 9 volumes of saline. Amounts of platinum were measured using inductively coupled plasma-mass spectrometry (ICP-MS) by the Pharmacokinetics and Bioanalysis Center, Shin Nippon Biomedical Laboratories, Ltd. (Wakayama, Japan).

\subsection{Cell culture and transfection}

Human embryonic kidney (HEK) 293 cells (American Type Culture Collection CRL-1573) were cultured in a complete medium consisting of Dulbecco's modified Eagle's medium (Wako) with 10\% fetal bovine serum (Life Technologies, Carlsbad, CA) in an atmosphere of $5 \% \mathrm{CO}_{2}-95 \%$ air at $37^{\circ} \mathrm{C}$.

As a transient expression system, pcDNA3.1(+) plasmid vector DNA (Life Technologies) or pFLAG-CMV-6b plasmid vector DNA (Sigma-Aldrich, St. Louis, MO), containing mOCT1, mOCT2, or mMATE1 cDNA, was purified using a HiSpeed Plasmid Maxi Kit (QIAGEN, Hilden, Germany). The day before transfection, HEK293 cells were seeded onto poly-D-lysine-coated $24-w e l l$ plates at a density of $2.0 \times 10^{5}$ cells per well. The cells were 
transfected with $800 \mathrm{ng}$ of DNA using $2 \mu \mathrm{l}$ of Lipofectamine 2000 (Life Technologies) per well according to the manufacturer's instructions. Forty-eight hours after the transfection, the cells were used for the experiments.

\subsection{Uptake experiment}

Uptake experiments were carried out as described previously [22]. Briefly, the composition of the incubation buffer was as follows: $145 \mathrm{mM} \mathrm{NaCl}, 3 \mathrm{mM} \mathrm{KCl}, 1 \mathrm{mM} \mathrm{CaCl}_{2}$, $0.5 \mathrm{mM} \mathrm{MgCl} 2,5 \mathrm{mM}$ D-glucose and $5 \mathrm{mM}$ HEPES (pH 7.4 adjusted with $\mathrm{NaOH}$ ). Cells expressing mOCT1 or mOCT2 were incubated with the culture medium containing $500 \mu \mathrm{M}$ cisplatin (Sigma-Aldrich) for $1 \mathrm{~h}$. Cells expressing mMATE1 were incubated with the culture medium containing $500 \mu \mathrm{M}$ cisplatin for 2 min after pre-treatment with $30 \mathrm{mM}$ ammonium chloride for $20 \mathrm{~min}$. After the incubation, the monolayers were rapidly washed twice with ice-cold incubation buffer containing 3\% BSA (Nacalai Tesque Inc., Kyoto, Japan) and then washed three times with ice-cold incubation buffer. The cells were solubilized in $0.5 \mathrm{~N} \mathrm{NaOH}$, and the amount of platinum was determined using ICP-MS.

The protein content of the cell monolayers solubilized in $0.5 \mathrm{~N} \mathrm{NaOH}$ was determined by the method of Bradford with a Bio-Rad Protein Assay Kit (Bio-Rad Laboratories, Hercules, CA).

\subsection{Statistical analysis}

Data were expressed as the mean \pm S.D. except mortality data. A Kaplan-Meier analysis and the log rank test were performed to determine the statistical significance of the mortality data. Data were analyzed statistically using the unpaired Student's $t$ test or multiple comparisons with Tukey's or Dunnett's two-tailed test after a one-way ANOVA. Probability values of less than 0.05 were considered statistically significant. 


\section{Results}

\subsection{Survival of mice treated with cisplatin}

All mice survived at least 3 days after the administration of $15 \mathrm{mg} / \mathrm{kg}$ of cisplatin. Lifespan was significantly shorter in Mate1(-/-) mice than Mate1(+/+) mice $(\mathrm{P}=0.02$, Fig. 1A). Body weights were comparable between the two groups (Fig. 1B). Plasma creatinine levels were significantly higher in Mate1(-/-) mice four days after the administration (Fig. 1C). In the following experiments, renal function was evaluated at Day 3.

\subsection{Nephrotoxicity and hepatotoxicity of cisplatin in Mate1(-/-) mice}

Three days after the administration of cisplatin, plasma creatinine, BUN, creatinine clearance, AST and ALT levels were examined. Body weights were reduced by the administration of cisplatin in Mate1(+/+) and Mate1(-/-) mice (Fig. 2A). In Mate(+/+) and Mate(-/-) mice, administration of cisplatin significantly increased plasma creatinine and BUN levels (Fig. 2B and 2C). In addition, creatinine clearance was markedly decreased in both groups (Fig. 2D). Moreover, creatinine and BUN levels were significantly elevated in cisplatin-treated Mate1(-/-) mice compared to cisplatin-treated Mate1(+/+) mice (Fig. 2B and

2C). Creatinine clearance tended to decrease (Fig. 2D). AST levels were weakly increased in Mate1(-/-) mice by the administration of cisplatin, but ALT levels were unchanged (Fig. 2E and $2 \mathrm{~F})$.

\subsection{Renal and hepatic accumulation of cisplatin in Mate1(+/+) and Mate1(-/-) mice}

One hour after the intravenous administration of cisplatin $(0.5 \mathrm{mg} / \mathrm{kg})$, the plasma concentration, renal accumulation and hepatic accumulation of platinum were compared 
between Mate1(+/+) and Mate1(-/-) mice. The plasma concentration and renal accumulation were significantly higher in Mate1(-/-) mice (Fig. 3A and 3B), while hepatic accumulation was comparable between the groups (Fig. 3C).

\subsection{Effect of pyrimethamine on renal function in mice treated with cisplatin}

Recently, it was reported that pyrimethamine was a potent and specific inhibitor of MATE [21]. One hour prior to cisplatin administration, pyrimethamine $(0.5 \mathrm{mg} / \mathrm{kg})$ was administered. This combination elevated plasma creatinine and BUN levels compared with cisplatin alone (Fig. 4A and 4B).

\subsection{Uptake of cisplatin by HEK293 cells expressing mOCT1, mOCT2 and mMATE1}

The uptake of platinum was examined in HEK293 cells expressing mOCT1 or mOCT2 after incubation with $500 \mu \mathrm{M}$ cisplatin for $1 \mathrm{~h}$. The accumulation of cisplatin was enhanced by mOCT1 and mOCT2 (Fig. 5A). Furthermore, the cellular accumulation of platinum in mMATE1-expressing cells was examined when the cells were treated with $500 \mu \mathrm{M}$ cisplatin for 2 min after pre-treatment with ammonium chloride. As shown in Fig. 5B, cisplatin was also markedly transported by mMATE1.

\section{Discussion}

Previous studies in vitro and in vivo by ourselves and others have showed OCT2-mediated renal accumulation of cisplatin to be a key factor in its nephrotoxicity [12-17, 22]. However, the molecular mechanism responsible for the efflux of cisplatin from tubular cells had not been clarified. In the present study, the role of MATE1 in the nephrotoxicity of cisplatin was examined in vivo. The nephrotoxicity was potentiated in Mate1(-/-) mice 
compared with Mate1(+/+) mice (Fig. 2B and 2C). Moreover, the renal accumulation of cisplatin was significantly increased in Mate1(-/-) mice (Fig. 3B), as previously reported for other substrates, such as metformin and cephalexin $[11,23]$. On the other hand, MATE1 had only a minor role in the hepatic accumulation and hepatotoxicity of cisplatin (Figs. 2E, 2F and 3C). The present study strongly suggested that MATE1 as well as OCT2 is involved in the renal handling of cisplatin, and a determinant of cisplatin-induced nephrotoxicity.

A congenital deficiency of transporters could affect the intracellular environment, such as cellular signalling or metabolic pathways, by altering the cellular accumulation of endogenous substrates. For example, disruption of ATP-binding cassette transporter 8 (ABC8/ABCG1), which facilitates cholesterol efflux, induced the expression of inflammation markers, cytokines and cytokine receptors including cathepsin B, tumor necrosis factor- $\alpha$ and monocyte chemoattractant protein-1, in the lung of mice [24]. There was another report that loss of peptide transporter 2 (PEPT2/SLC15A2) reduced the renal concentrations of cysteine and glycine, substrates for glutathione synthesis, suggesting that sensitivity to oxidative stress was enhanced [25]. In the present study, we used not only Mate1(-/-) mice, but also a potent and specific MATE inhibitor, pyrimethamine [21]. The nephrotoxicity of cisplatin was also potentiated by the concomitant administration of pyrimethamine (Fig. 4). These findings suggested that not only a congenital deficiency but also a temporary functional deficiency of MATE1 could exacerbate the nephrotoxicity of cisplatin.

The use of an OCT2 inhibitor is one way to prevent the nephrotoxicity of cisplatin. We previously reported that the concomitant administration of imatinib, a OCT substrate, prevented cisplatin-induced nephrotoxicity based on competitive inhibition of the OCT2-mediated renal accumulation of cisplatin [16]. Another OCT substrate, cimetidine, also ameliorated the nephrotoxicity of cisplatin at a high dose [17]. However, the substrate specificities of MATE1 and OCT2 are similar [18-20]. OCT substrates could competitively 
inhibit the transport activity of MATE, depending on their affinity for OCT or MATE and blood concentration. In fact, it was recently reported that cimetidine inhibited hMATE1 more potently than hOCT2 $[20,26]$. In addition, the renal concentrations of several cationic drugs were higher than the plasma concentrations [11, 27]. Therefore, cationic drugs would potentially inhibit MATEs rather than OCT2. The MATE1 inhibitor pyrimethamine potentiated cisplatin-induced nephrotoxicity (Fig. 4). For renoprotection using an OCT2 inhibitor during treatment with cisplatin, the possibility that nephrotoxicity is actually potentiated by the inhibition of MATEs when OCT2 inhibition is not complete should be considered.

We previously reported that the cellular uptake of cisplatin for $1 \mathrm{~h}$ was increased by the expression of hMATE1 and hMATE2-K without pre-treatment with ammonium chloride [14]. On the other hand, there was no significant stimulation of the intracellular accumulation of platinum in hMATE1 and hMATE2-K-expressing cells after incubation with cisplatin for 2 min under conditions of ammonium chloride-generated intracellular acidification [22]. An inhibitory effect of cisplatin on the transport of tetraethylammonium by hMATE1 and hMATE2-K was observed [14]. It is still unclear whether cisplatin is a substrate for human MATEs. More importantly, cisplatin is aquated to the active species in the cell in a non-enzymatic reaction. Therefore, it should be also considered whether an active form of cisplatin was transported by MATEs. In the present study, cisplatin was transported by mMATE1 as well as mOCT1 and mOCT2 in the uptake experiments (Fig. 5), and the renal accumulation of cisplatin was increased in Mate1(-/-) mice (Fig. 3B). These results indicated that cisplatin was exported from renal epithelial cells in mice. It was previously reported that the renal clearance of cisplatin exceeded the glomerular filtration rate in humans and rats [28, 29], suggesting that cisplatin was secreted across renal tubular cells. Therefore, the hMATE family would have a role in the efflux of cisplatin from renal epithelial cells. 
Further study is needed to reveal the contribution of hMATEs to the renal handling of cisplatin in humans.

In conclusion, the present study using Mate1(-/-) mice strongly suggested that MATE1 mediates the efflux of cisplatin from renal tubular epithelial cells and is involved in cisplatin-induced nephrotoxicity. A genetic deficiency or drug-drug interaction in MATE would potentiate the nephrotoxicity in cisplatin-based chemotherapy.

\section{Acknowledgements}

This work was supported in part by a grant-in-aid for Scientific Research (KAKENHI) from the Ministry of Education, Culture, Sports, Science and Technology of Japan.

\section{Author Contributions}

Study conception and design: T.N. and A.Y.; Acquisition, analysis and/or interpretation of data: T.N., A.Y. and S.H.; Drafting/revision of the work for intellectual content and context: T.N., A.Y., T.K. and K.I.; Final approval and overall responsibility for the published work: K.I. All authors read and approved the final manuscript.

\section{References}

[1] de Jongh FE, van Veen RN, Veltman SJ, de Wit R, van der Burg ME, van den Bent MJ, et al. Weekly high-dose cisplatin is a feasible treatment option: analysis on prognostic factors for toxicity in 400 patients. Br J Cancer 2003;88:1199-206.

[2] Dobyan DC, Levi J, Jacobs C, Kosek J, Weiner MW. Mechanism of cis-platinum 
nephrotoxicity: II. Morphologic observations. J Pharmacol Exp Ther 1980;213:551-6.

[3] Litterst CL, Gram TE, Dedrick RL, Leroy AF, Guarino AM. Distribution and disposition of platinum following intravenous administration of cis-diamminedichloroplatinum(II) (NSC 119875) to dogs. Cancer Res 1976;36:2340-4.

[4] Gorboulev V, Ulzheimer JC, Akhoundova A, Ulzheimer-Teuber I, Karbach U, Quester S, et al. Cloning and characterization of two human polyspecific organic cation transporters. DNA Cell Biol 1997;16:871-81.

[5] Motohashi H, Sakurai Y, Saito H, Masuda S, Urakami Y, Goto M, et al. Gene expression levels and immunolocalization of organic ion transporters in the human kidney. $\mathbf{J}$ Am Soc Nephrol 2002;13:866-74.

[6] Otsuka M, Matsumoto T, Morimoto R, Arioka S, Omote H, Moriyama Y. A human transporter protein that mediates the final excretion step for toxic organic cations. Proc Natl Acad Sci U S A 2005;102:17923-8.

[7] Masuda S, Terada T, Yonezawa A, Tanihara Y, Kishimoto K, Katsura T, et al. Identification and functional characterization of a new human kidney-specific $\mathrm{H}^{+}$/organic cation antiporter, kidney-specific multidrug and toxin extrusion 2. J Am Soc Nephrol $2006 ; 17: 2127-35$

[8] Tsuda M, Terada T, Asaka J, Ueba M, Katsura T, Inui K. Oppositely directed $\mathrm{H}^{+}$ gradient functions as a driving force of rat $\mathrm{H}^{+}$/organic cation antiporter MATE1. Am J Physiol Renal Physiol 2007;292:F593-8.

[9] Green RM, Lo K, Sterritt C, Beier DR. Cloning and functional expression of a mouse liver organic cation transporter. Hepatology 1999;29:1556-62.

[10] Mooslehner KA, Allen ND. Cloning of the mouse organic cation transporter 2 gene, Slc22a2, from an enhancer-trap transgene integration locus. Mamm Genome 1999;10:218-24. [11] Tsuda M, Terada T, Mizuno T, Katsura T, Shimakura J, Inui K. Targeted disruption of 
the multidrug and toxin extrusion 1 (Mate1) gene in mice reduces renal secretion of metformin. Mol Pharmacol 2009;75:1280-6.

[12] Ciarimboli G, Ludwig T, Lang D, Pavenstadt H, Koepsell H, Piechota HJ, et al. Cisplatin nephrotoxicity is critically mediated via the human organic cation transporter 2. Am J Pathol 2005;167:1477-84.

[13] Yonezawa A, Masuda S, Nishihara K, Yano I, Katsura T, Inui K. Association between tubular toxicity of cisplatin and expression of organic cation transporter rOCT2 (Slc22a2) in the rat. Biochem Pharmacol 2005;70:1823-31.

[14] Yonezawa A, Masuda S, Yokoo S, Katsura T, Inui K. Cisplatin and oxaliplatin, but not carboplatin and nedaplatin, are substrates for human organic cation transporters (SLC22A1-3 and multidrug and toxin extrusion family). J Pharmacol Exp Ther 2006;319:879-86.

[15] Filipski KK, Mathijssen RH, Mikkelsen TS, Schinkel AH, Sparreboom A. Contribution of organic cation transporter 2 (OCT2) to cisplatin-induced nephrotoxicity. Clin Pharmacol Ther 2009;86:396-402.

[16] Tanihara $\mathrm{Y}$, Masuda S, Katsura $\mathrm{T}$, Inui $\mathrm{K}$. Protective effect of concomitant administration of imatinib on cisplatin-induced nephrotoxicity focusing on renal organic cation transporter OCT2. Biochem Pharmacol 2009;78:1263-71.

[17] Ciarimboli G, Deuster D, Knief A, Sperling M, Holtkamp M, Edemir B, et al. Organic cation transporter 2 mediates cisplatin-induced oto- and nephrotoxicity and is a target for protective interventions. Am J Pathol 2010;176:1169-80.

[18] Koepsell H, Lips K, Volk C. Polyspecific organic cation transporters: structure, function, physiological roles, and biopharmaceutical implications. Pharm Res 2007;24:1227-51.

[19] Terada T, Inui K. Physiological and pharmacokinetic roles of $\mathrm{H}^{+}$/organic cation 
antiporters (MATE/SLC47A). Biochem Pharmacol 2008;75:1689-96.

[20] Tsuda M, Terada T, Ueba M, Sato T, Masuda S, Katsura T, et al. Involvement of human multidrug and toxin extrusion 1 in the drug interaction between cimetidine and metformin in renal epithelial cells. J Pharmacol Exp Ther 2009;329:185-91.

[21] Ito S, Kusuhara H, Kuroiwa $\mathrm{Y}$, Wu C, Moriyama Y, Inoue K, et al. Potent and specific inhibition of mMate1-mediated efflux of type I organic cations in the liver and kidney by pyrimethamine. J Pharmacol Exp Ther 2010;333:341-50.

[22] Yokoo S, Yonezawa A, Masuda S, Fukatsu A, Katsura T, Inui K. Differential contribution of organic cation transporters, OCT2 and MATE1, in platinum agent-induced nephrotoxicity. Biochem Pharmacol 2007;74:477-87.

[23] Watanabe S, Tsuda M, Terada T, Katsura T, Inui K. Reduced renal clearance of a zwitterionic substrate cephalexin in Mate1-deficient mice. J Pharmacol Exp Ther 2010;334:651-6.

[24] Baldan A, Gomes AV, Ping P, Edwards PA. Loss of ABCG1 results in chronic pulmonary inflammation. J Immunol 2008;180:3560-8.

[25] Frey IM, Rubio-Aliaga I, Siewert A, Sailer D, Drobyshev A, Beckers J, et al. Profiling at mRNA, protein, and metabolite levels reveals alterations in renal amino acid handling and glutathione metabolism in kidney tissue of Pept $2^{-/-}$mice. Physiol Genomics 2007;28:301-10.

[26] Matsushima S, Maeda K, Inoue K, Ohta K, Yuasa H, Kondo T, et al. The inhibition of human multidrug and toxin extrusion 1 is involved in the drug-drug interaction caused by cimetidine. Drug Metab Dispos 2009;37:555-9.

[27] Ji L, Masuda S, Saito H, Inui K. Down-regulation of rat organic cation transporter rOCT2 by 5/6 nephrectomy. Kidney Int 2002;62:514-24.

[28] Jacobs C, Kalman SM, Tretton M, Weiner MW. Renal handling of 
cis-diamminedichloroplatinum(II). Cancer Treat Rep 1980;64:1223-6.

[29] Daley-Yates PT, McBrien DC. The mechanism of renal clearance of cisplatin (cis-dichlorodiammine platinum II) and its modification by furosemide and probenecid. Biochem Pharmacol 1982;31:2243-6. 


\section{Legends for figures}

Fig. 1. Survival rates, body weights and plasma creatinine levels of cisplatin-treated mice. (A) Kaplan-Meier survival curve for Mate1(+/+) (solid; $\mathrm{n}=6)$ and Mate1(-/-) (dotted; $\mathrm{n}=6$ ) mice after the administration of cisplatin $(15 \mathrm{mg} / \mathrm{kg})$. The body weights (B) and plasma creatinine levels (C) of Mate1(+/+) (open circles) and Mate1(-/-) mice (closed circles) were also examined at Days 1, 2, 4 and 7. Each point represents the mean \pm S.D. $\quad{ }^{* *} P<0.01$, significantly different from Mate1(+/+) mice.

Fig. 2. Nephrotoxicity and hepatotoxicity of cisplatin in Mate1(+/+) and Mate1(-/-) mice. Biochemical parameters (A: Body weight; B: Plasma creatinine; C: BUN; D: Creatinine clearance; E: AST; F: ALT) were examined three days after the administration of cisplatin (15 $\mathrm{mg} / \mathrm{kg}$ ). Each bar represents the mean \pm S.D. for five or six mice from two independent experiments. $\quad \dagger P<0.05$; $\dagger \dagger P<0.01$, significantly different from pre-administration. $* P<0.05 ; * * P<0.01 ; * * * P<0.001$, significantly different.

Fig. 3. Plasma concentration (A), renal accumulation (B) and hepatic accumulation (C) of cisplatin in Mate1(+/+) and Mate1(-/-) mice. The plasma, kidney and liver were collected 1 $\mathrm{h}$ after the administration of cisplatin $(0.5 \mathrm{mg} / \mathrm{kg})$, and the kidney and liver were homogenized in 9 volumes of saline. The concentration of platinum in each sample was determined by ICP-MS. Each bar represents the mean \pm S.D. for five mice. $* P<0.05$; $* * P<0.01$, significantly different.

Fig. 4. Effect of pyrimethamine on renal function in wild-type mice treated with cisplatin. Plasma creatinine (A) and BUN (B) levels were examined three days after the administration of cisplatin $(15 \mathrm{mg} / \mathrm{kg})$ with pyrimethamine $(0.5 \mathrm{mg} / \mathrm{kg})$ or cisplatin $(15 \mathrm{mg} / \mathrm{kg})$ alone. Each 
bar represents the mean \pm S.D. for eight or nine mice from two independent experiments. $* P<0.05 ; * * * P<0.001$, significantly different.

Fig. 5. Uptake of cisplatin by HEK293 cells expressing mOCT1, mOCT2 and mMATE1. (A) HEK293 cells were transfected with empty vector (open bar), mOCT1 (gray bar), or mOCT2 (black bar). The cells were treated with medium containing $500 \mu \mathrm{M}$ cisplatin for 1 h. After being washed, the cells were solubilized in $0.5 \mathrm{~N} \mathrm{NaOH}$, and the amount of platinum was determined by ICP-MS. (B) HEK293 cells were transfected with empty vector (open bar) and mMATE1 (closed bar). The cells were treated with medium containing 500 $\mu \mathrm{M}$ cisplatin for 2 min after pretreatment with $30 \mathrm{mM}$ of ammonium chloride for $20 \mathrm{~min}$. After being washed, the cells were solubilized in $0.5 \mathrm{~N} \mathrm{NaOH}$, and the amount of platinum was determined by ICP-MS. Each bar represents the mean \pm S.D. for four wells. $* * P<0.01 ; * * * P<0.001$, significantly different from vector-transfected cells. 
Figure 1

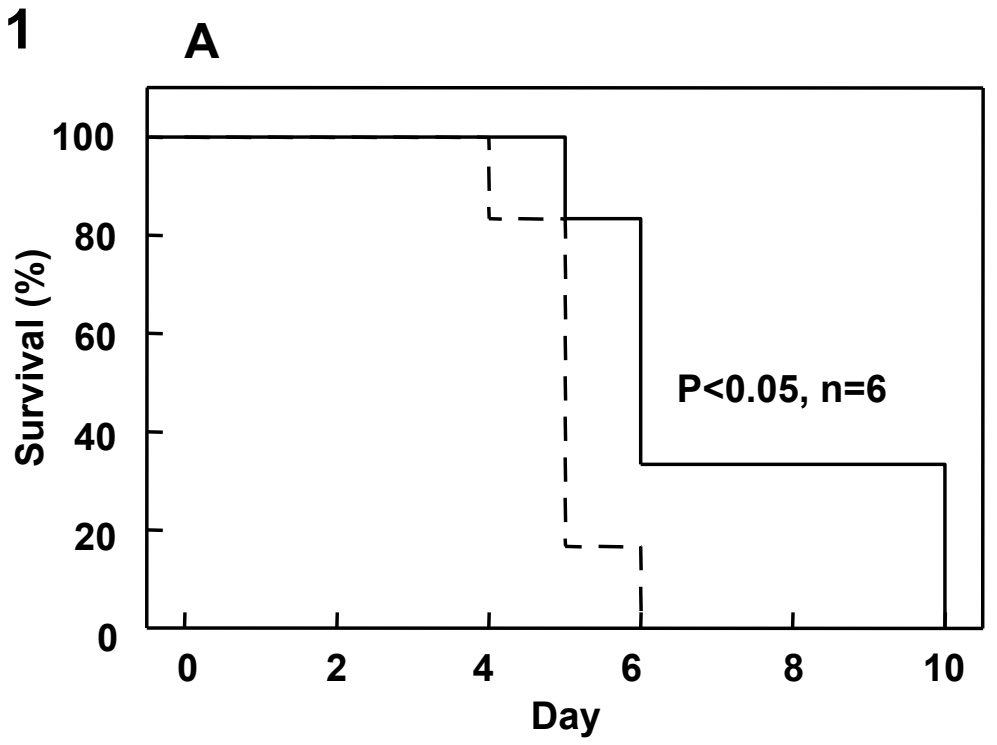

- Mate1(+/+)

- Mate1(-/-)

B

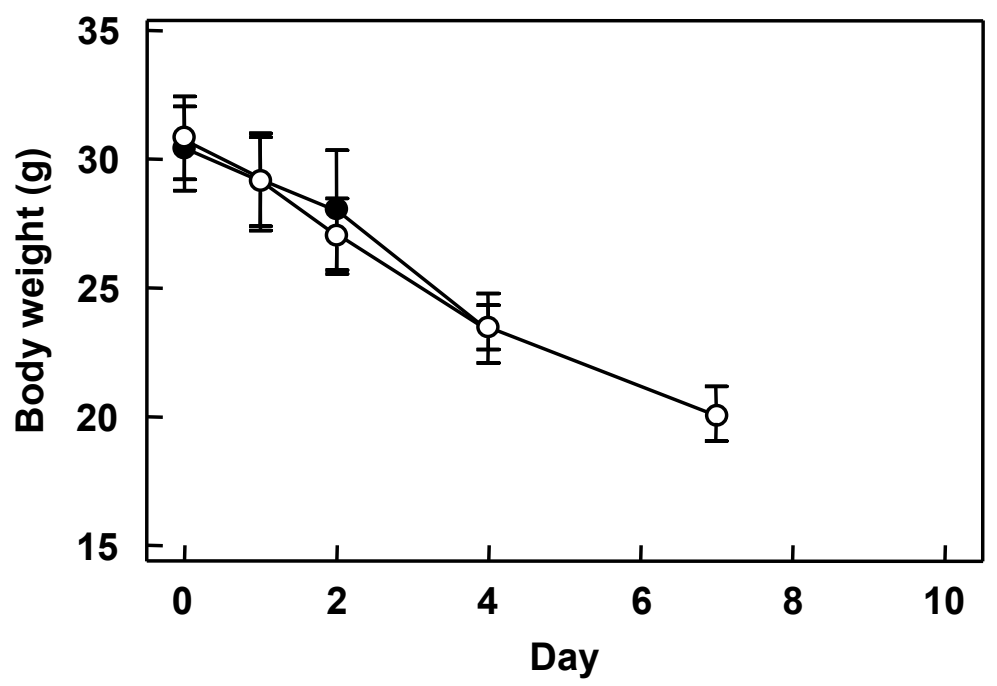

○ Mate1(+/+)

- Mate1(-/-)

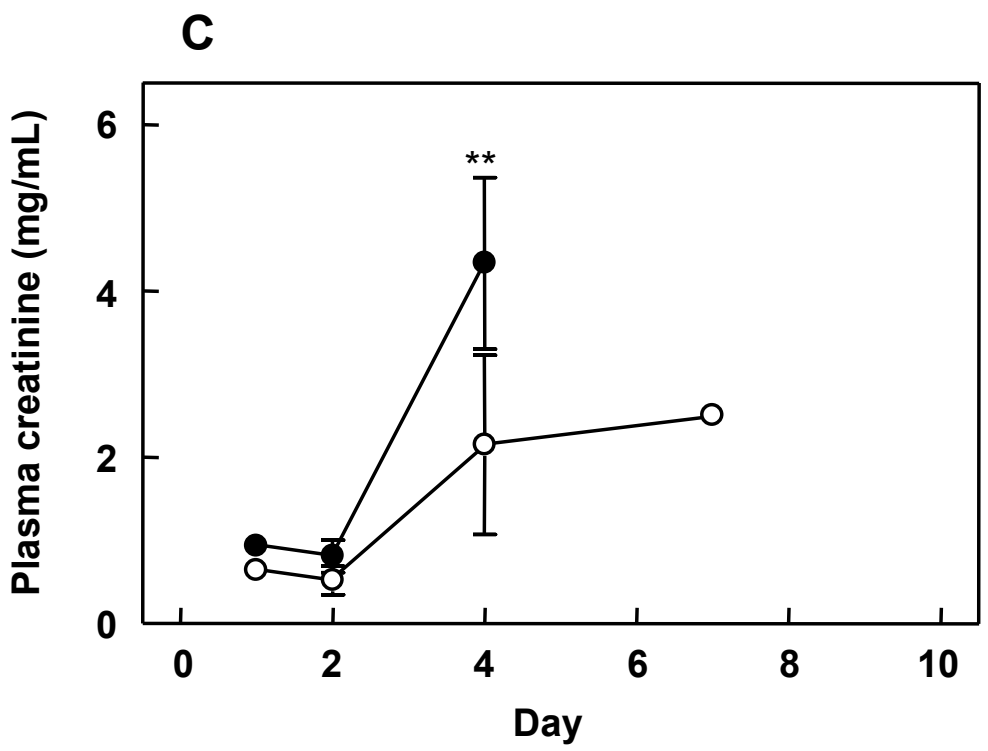

○ Mate1(+/+)

- Mate1(-/-) 
Figure 2
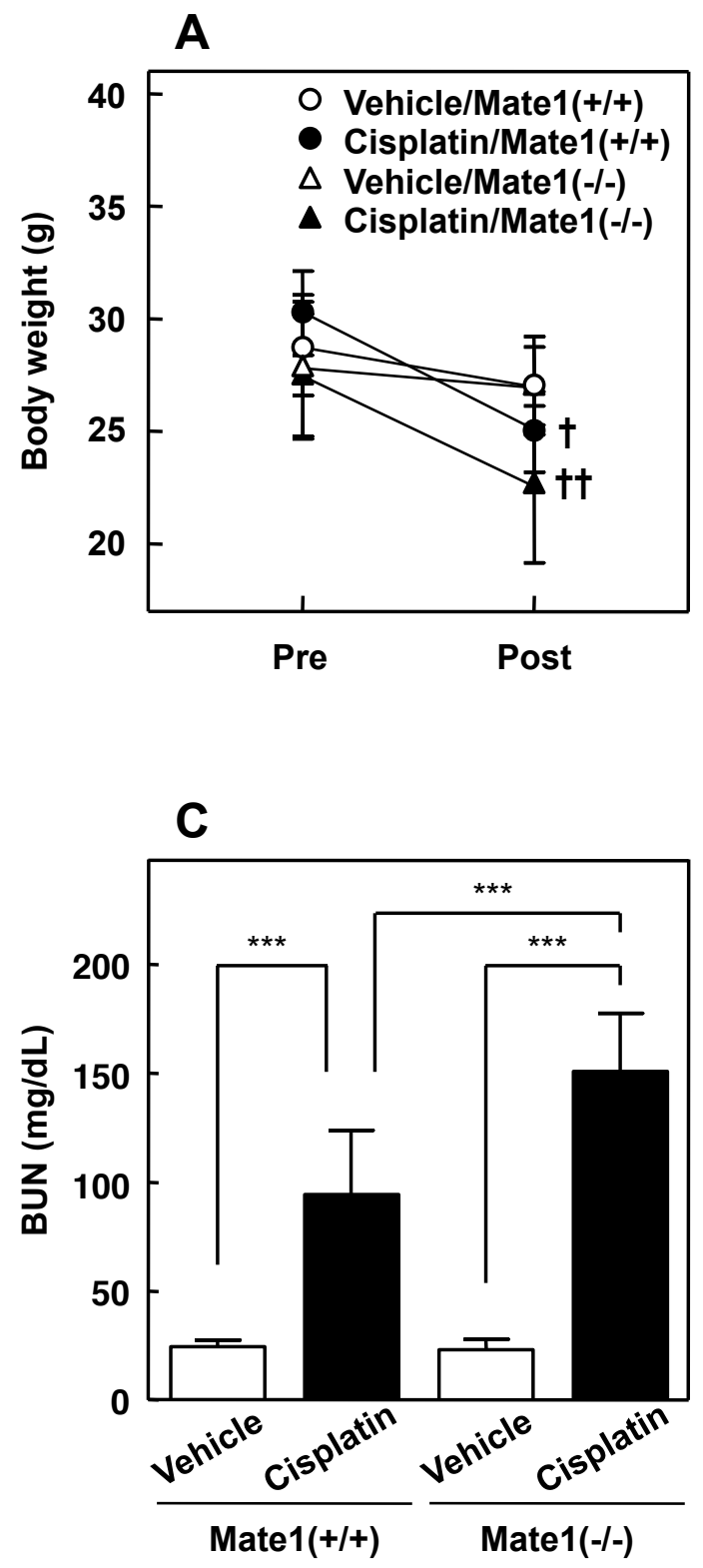

E

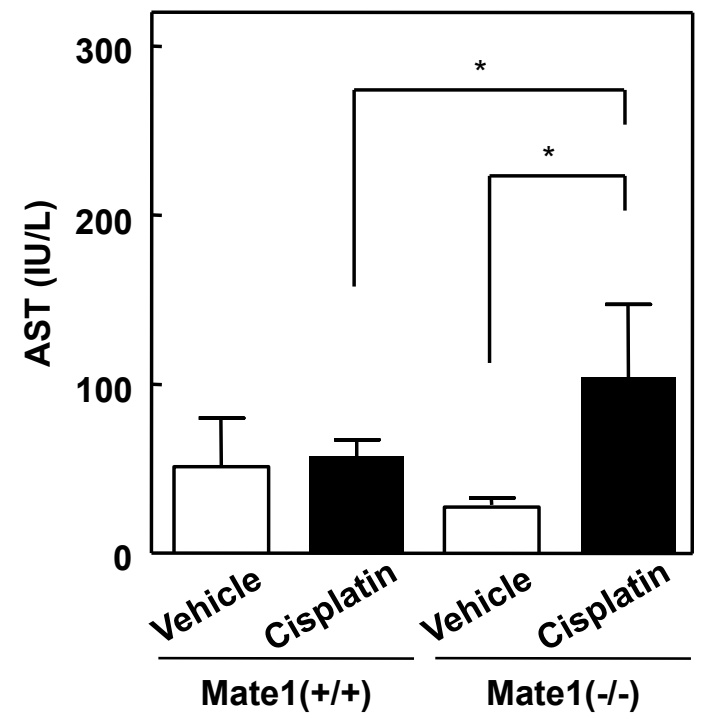

B

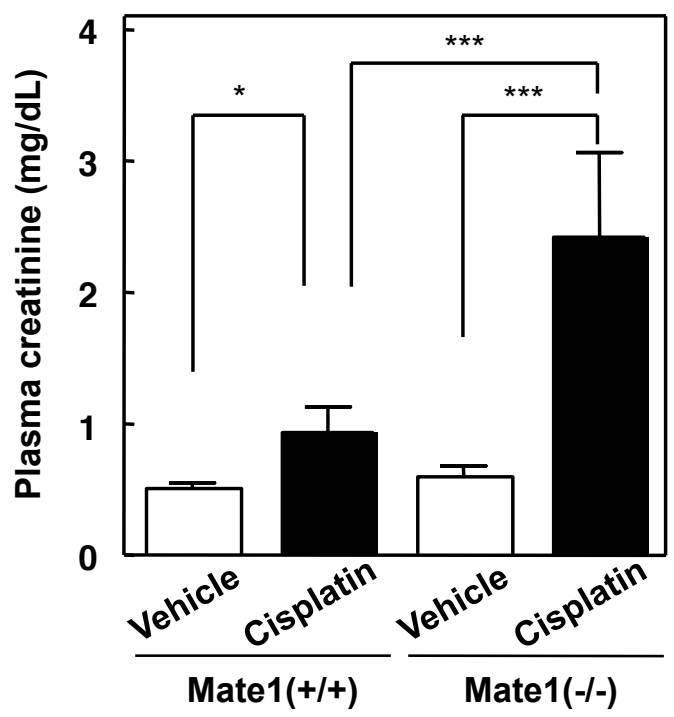

D

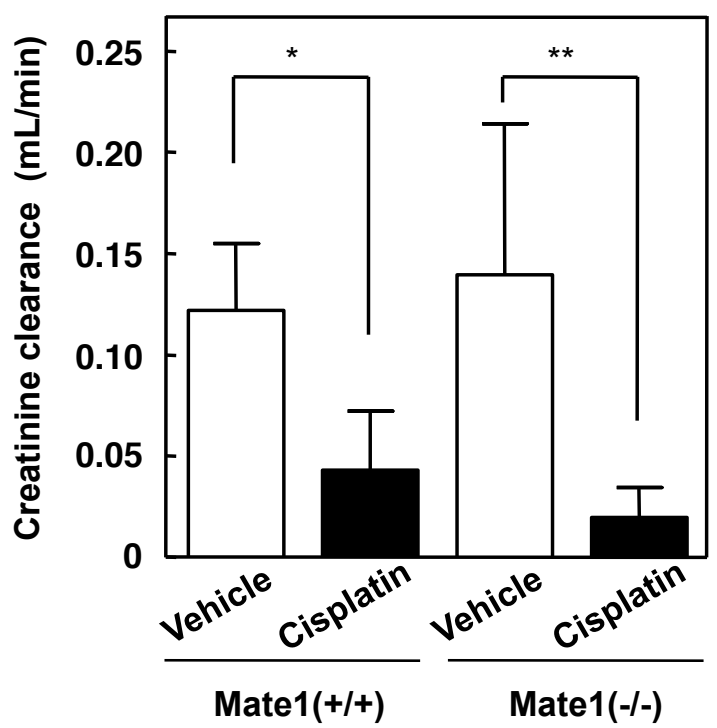

F

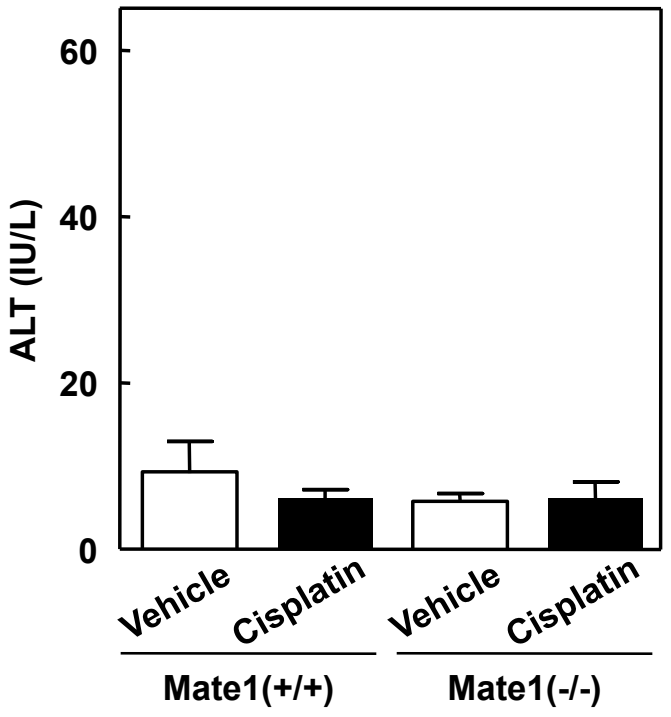




\section{Figure 3}

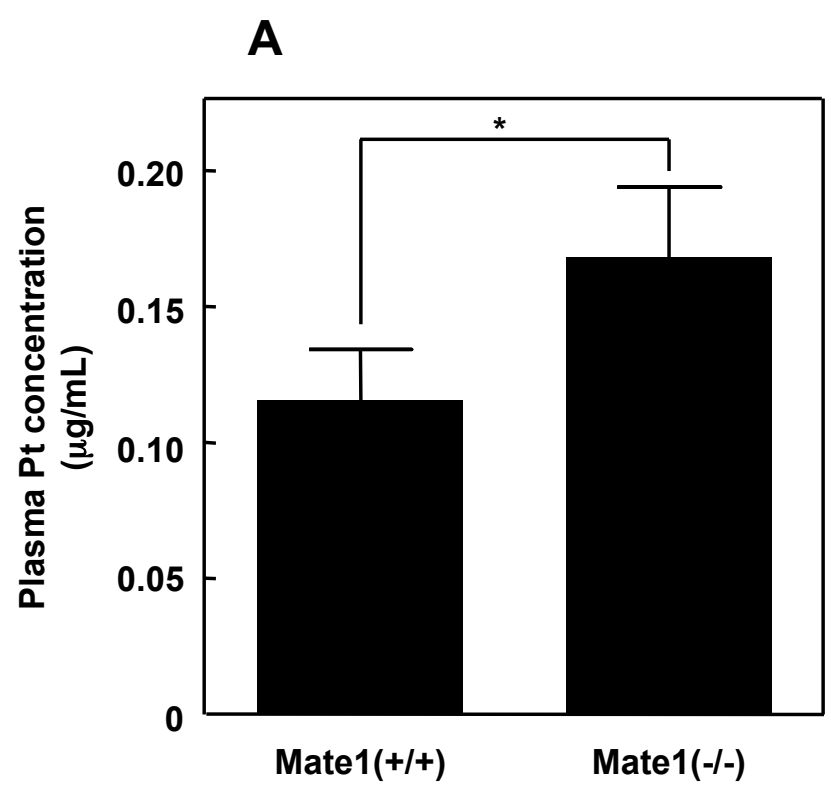

B

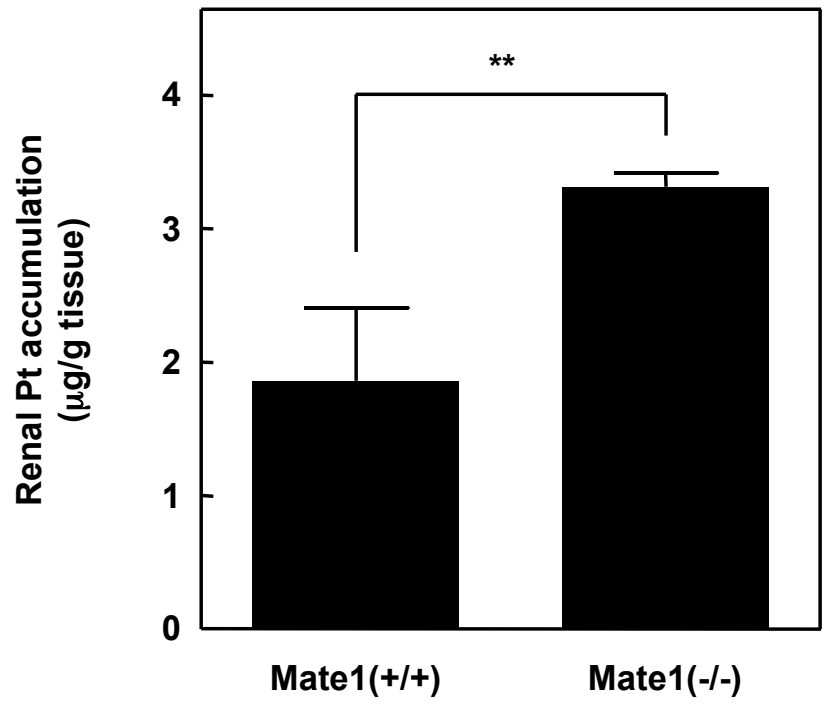

C

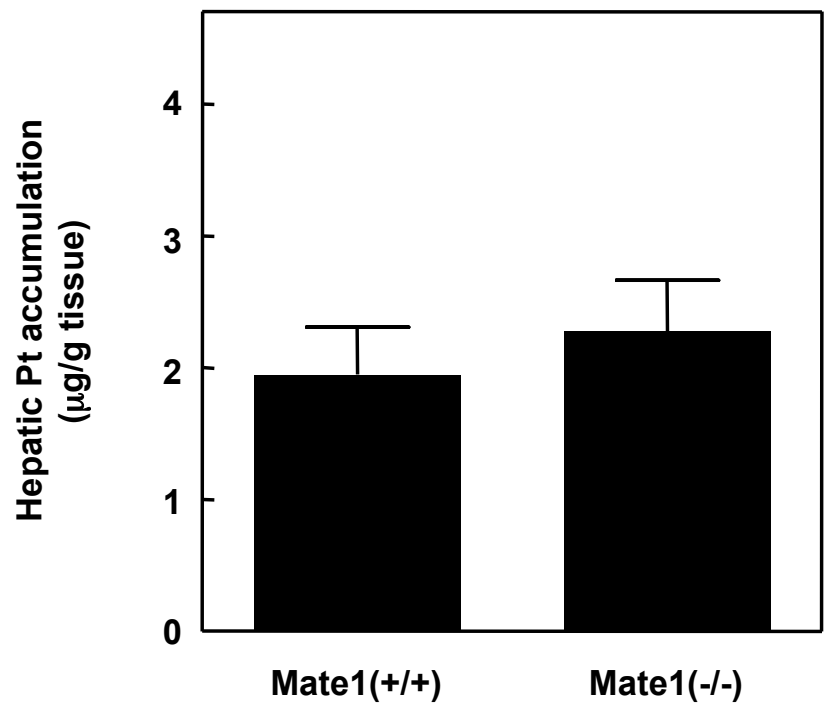




\section{Figure 4}
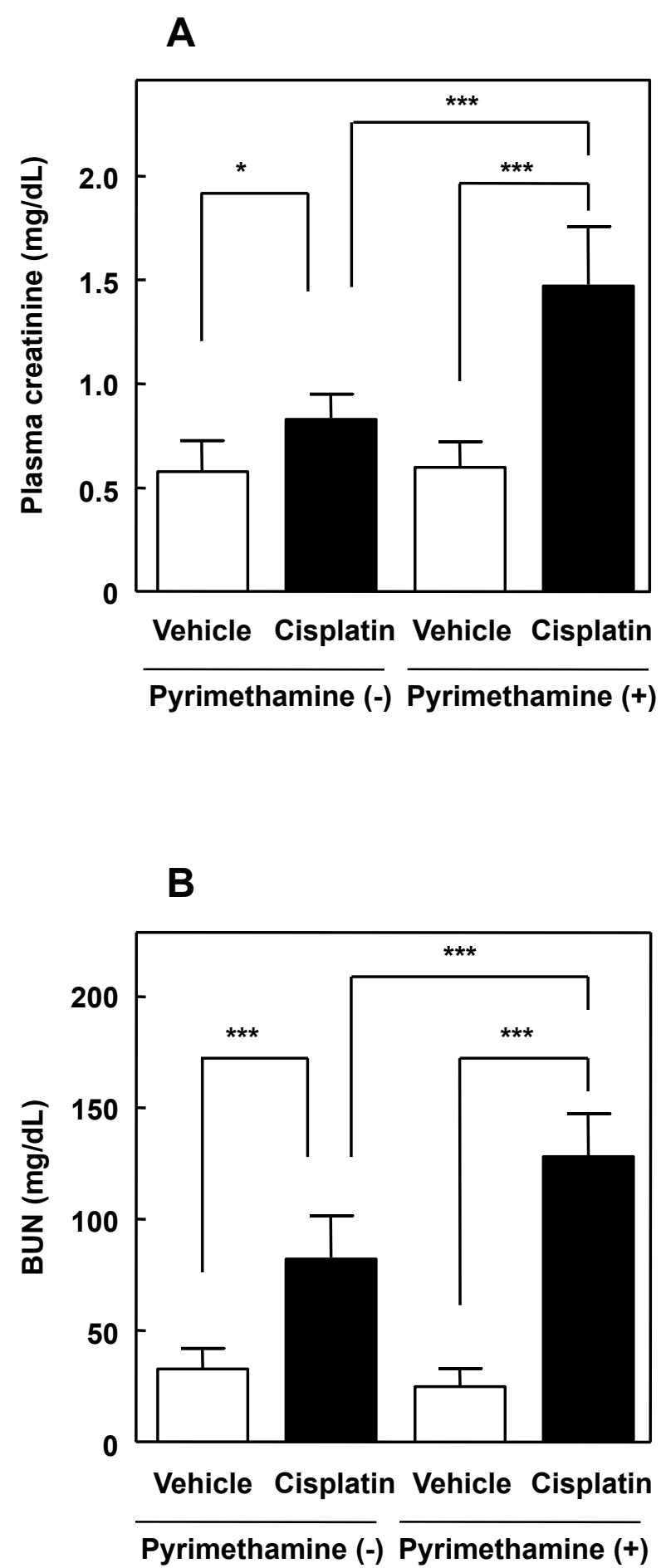
Figure 5

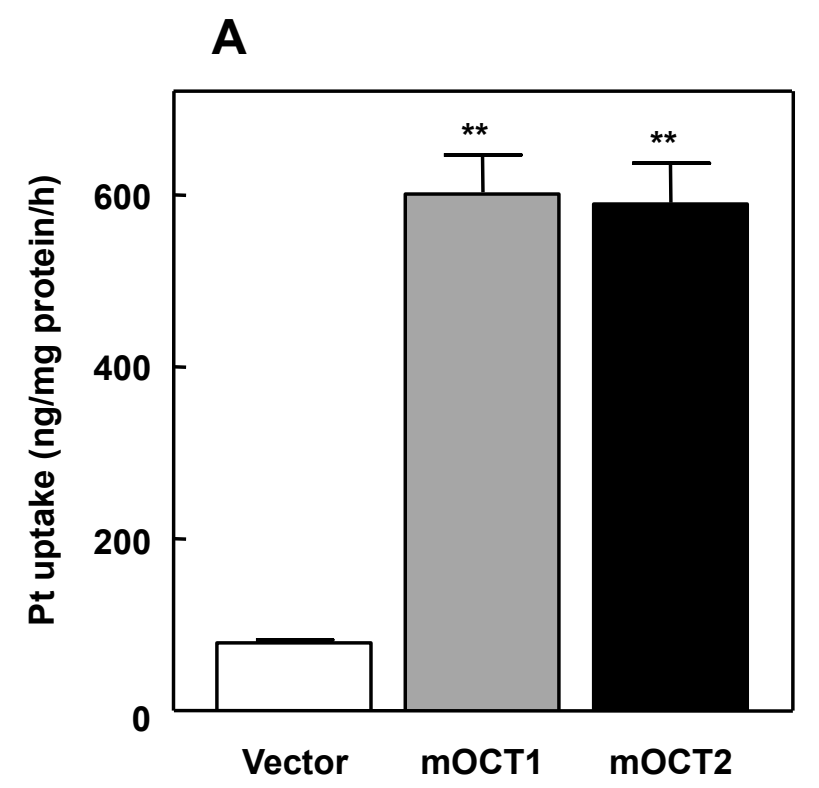

B

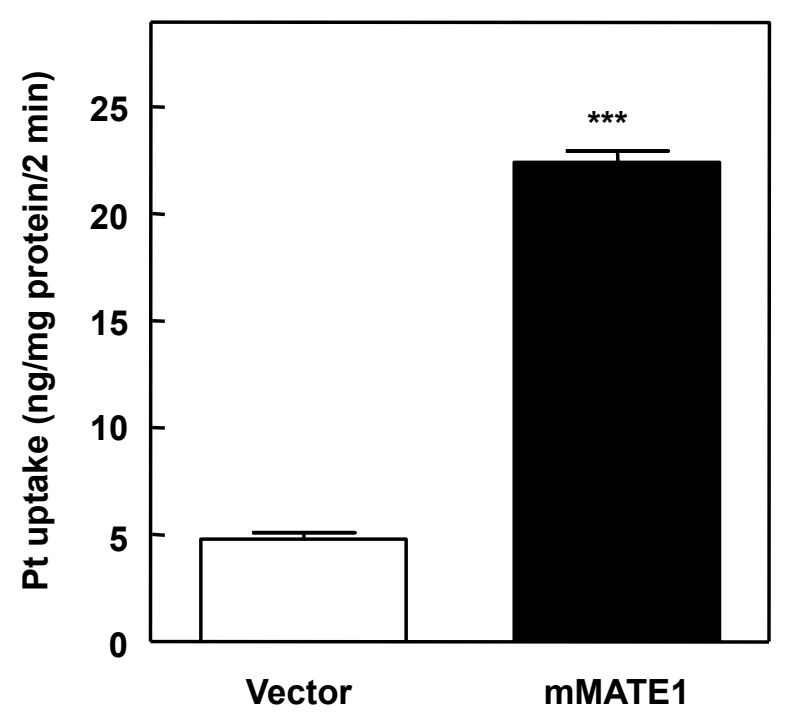

